\title{
UNA GRAN PRUEBA DE IMPRENTA. VÍNCULOS INTERDISCURSIVOS EN LA POESÍA TEMPRANA DE ROGER WOLFE
}

\section{A Huge Page Proof. Interdiscursive Links in Roger Wolfe's Early Poetry}

\author{
MARIANO DOMINGO \\ Universidad Nacional de Mar del Plata \\ marianodomingo96@gmail.com \\ ORCID ID: 0000-0002-9275-7398
}

Recibido: 08-09-2021 / Aceptado: 11-11-2021

DOI: https://doi.org/10.51743/cilh.vi47.239

\begin{abstract}
RESUMEN
La obra de Roger Wolfe, tradicional y reductivamente asociada a la corriente del «realismo sucio» español, ha hecho siempre de la reapropiación de materiales ajenos una operatoria fundante de su praxis poética. El presente trabajo se propone revisar esa matriz otra de significados reinterpretados por el poeta anglo-español en un corpus de textos extraídos de tres de sus primeros poemarios publicados entre 1992 y 1994 (Días perdidos en los transportes públicos, Hablando de pintura con un ciego y Arde Babilonia). Con este objeto se apelará a la «interdiscursividad» y la «intermedialidad».
\end{abstract}

PALABRAS CLAVE: Roger Wolfe; poesía española; interdiscursividad; intermedialidad.

ABSTRACT

Roger Wolfe's poetry, traditionally and reductively associated to Spanish «realismo sucio», has always made the reappropriation of foreign materials a founding operation of his poetic praxis. This article proposes to revise that other matrix of meanings reinterpreted by the English-Spanish poet in a corpus taken from three of his first books published between 1992 and 1994 (Dias perdidos en los transportes públicos, Hablando de pintura con un ciego and Arde Babilonia). For such analysis we will appeal to the «interdiscursivity» and «intermediality».

KEY WORDS: Roger Wolfe; Spanish poetry; Interdiscursivity; Intermediality. 


\title{
UNA GRAN PRUEBA DE IMPRENTA. VÍNCULOS INTERDISCURSIVOS \\ EN LA POESÍA TEMPRANA DE ROGER WOLFE ${ }^{1}$
}

\author{
MARIANO DOMINGO \\ Universidad Nacional de Mar del Plata
}

$[\ldots]$ porque soy de los que opinan

que la literatura

es una gran prueba de imprenta

ya compuesta que entre todos nos afanamos inútilmente en corregir.

(«Pruebas», Arde Babilonia, Roger Wolfe)

\footnotetext{
${ }^{1}$ Este trabajo se enmarca dentro una beca de investigación otorgada por la Universidad Nacional de Mar del Plata (UNMDP), con inserción en un proyecto de investigación mayor del Grupo Semiótica del Discurso, dirigido por la Dra. Laura Scarano, radicado en la Facultad de Humanidades de la misma universidad, de título «De los Salones a la Web: sociabilidad(es), redes y campo literario en España (siglos XIX a XXI)», dirigido por la Dra. Marcela Romano y codirigido por la Dra. Verónica Leuci.
} 


\section{INTRODUCCIÓN. LA PLURALIDAD DE DISCURSOS COMO PUNTO DE PARTIDA}

EN EL SINGULAR TRAYECTO que describe la poética de Roger Wolfe (Westerham, 1962), pueden reconocerse influencias diversas para las sucesivas etapas de su desarrollo como autor ${ }^{2}$. Su obra poética se compone de casi una veintena de títulos entre poemarios y antologías, algunos de ellos bilingües, varios libros de ensayos y otros de relatos $^{3}$. Fue distinguido con el premio Anthropos de poesía en 1991 y el Ciudad de Barbastro de novela por Fuera del tiempo y de la vida. Algunos sectores críticos lo consideraron, en sus comienzos, cercano a la «poesía de la experiencia» predominante en la España de los años ochenta y noventa, pero sus indagaciones en torno a las posibilidades de un realismo más prosaico, más austero, casi antirretórico, lo desviarán hacia formas de expresión propias. Aun así, su producción ha colisionado, en reiteradas ocasiones, con ciertas opiniones especializadas que, reductivamente, insisten en acotar los alcances de su poética, circunscribiéndola exclusivamente a la línea del dirty realism norteamericano ${ }^{4}$. La tendencia, de mediados de siglo XX, derivación del

\footnotetext{
2 Nacido en el condado de Kent, Inglaterra, vive desde los cuatro años en España. Dio inicio a sus estudios en Alicante para terminarlos en su país de origen, allí se formó en lengua y literatura inglesa y francesa.

${ }^{3}$ Entre sus títulos más importantes se cuentan Quién no necesita algo en que apoyarse (1993), El índice de Dios (1993), Mi corazón es una casa helada en el fondo del infierno (1996), Luz en la arena (2013) y El Sur es un sitio grande (2014) para narrativa y los volúmenes de ensayos Todos los monos del mundo (1995), Hay una guerra (1997), Siéntate y escribe (2011) y Escrito con la lengua (2012).

${ }^{4}$ El vínculo entre Wolfe y el final de la poesía de la experiencia es planteado por, entre otros, Luis Antonio de Villena en «Un hosco ardor contemporáneo», Miguel García Posada en «Del nuevo realismo: La confirmación poética de Roger Wolfe» y Jordi Gracia en Hijos de la razón. Por otro lado, autores como Miguel García-Posada («El realismo sucio, canonizado»), Víctor García de la Concha («Hablando de pintu-
} 
minimalismo estadounidense, intenta un regreso del arte sobre el existir más convencional del hombre. Un realismo sobrio, sin maquillar, sucio por lo «manchado» de vida, pero no intrínsecamente feísta ni tremendista, como se ha insistido reiteradamente.

Wolfe, dueño de un estilo sobrio, debe una influencia fundamental tanto a Carver como a Bukowski (nombres comúnmente asociados al dirty realism $)^{5}$. Sin embargo, la etiqueta de «realista sucio» que por años se le ha adosado dentro del escenario intelectual español no hace sino obturar muchas de las propuestas y operaciones de sentido que hacen su escritura personal y multifacética. Los únicos paralelos entre ellos parecen ser el tratamiento del alcoholismo como materia poetizable y el argot como medio genuino de expresión. El singular trabajo de recuperación y resignificación de materiales ajenos, ya literarios, ya de otra índole, insoslayable para la praxis poética de Wolfe, es una de esas aristas que se muestran menos exploradas por la crítica especializada. En su poesía, es posible advertir lazos que operan entre su escritura y una serie de textos pertenecientes a épocas y tradiciones diversas, desde los clásicos de la Antigüedad grecolatina y del Siglo de Oro español, hasta el decadentismo francés y la literatura norteamericana última. Él mismo lo ha puesto en palabras; consultado sobre la dificultad de asimilar la obra ajena, responde:

Para un creador, todo es arcilla maleable; incluida la masa de otro creador. Por otra parte, todo ya está escrito y hecho en realidad; existe una teoría

ra con un ciego») y Rafael Conte («Días...») son algunos de los nombres que identifican la obra de Wolfe como continuación directa del dirty realism norteamericano.

${ }^{5}$ Como ha advertido Juan Miguel López Merino en su estudio «Sobre la presencia de Roger Wolfe en la poesía española (1990-2000) y revisión del marbete "realismo sucio"", la incorporación de Bukowski a la nómina de realistas sucios que habría influido en la praxis poética wolfiana se demuestra errónea. López Merino señala la irreflexiva adscripción de Bukowski a tal tendencia por parte de la crítica española e internacional, adscripción apresurada además por la falta de traducciones al español de su poesía hasta mediados de la década del 90. El propio Wolfe señala el equívoco de adscribir a Bukowski al «realismo sucio» porque, entiende, el realismo de este abreva en Hemingway y es esencialmente distinto al desarrollado por Carver. 
según la cual el arte es un gran río en el cual lo que llamamos autores no son sino áreas de «densificación» de partículas preexistentes; o una especie de gran prueba de imprenta, ya compuesta, que todos vamos corrigiendo individualmente con nuestras aportaciones [2015].

Una evidente matriz «transtextual», en términos de Gerard Genette, subyace a buena parte de la lírica de Wolfe, que no puede ser comprendida por entero sin profundizar sobre esos vínculos por los que el texto trasciende sus propios límites como unidad singular, autónoma entra en contacto con multiplicidad de textos otros [Genette, 1989: 9-10]. Esta noción se encuentra íntimamente emparentada con las ideas desarrolladas por Julia Kristeva en torno al ya clásico concepto de intertextualidad, influenciado directamente por el postulado bajtiniano de la dialogicidad consustancial al enunciado. Si entonces, siguiendo a Bajtín, todo enunciado que se pronuncia está, de alguna forma, condicionado por otros anteriores de los que es respuesta y, a la vez, en sí mismo, prefigura potenciales enunciados futuros, por consiguiente, a todo texto pueden reconocérsele antecedentes intertextuales y por lo mismo, como reconoce José Enrique Martínez Fernández, cualquier «texto tiene la posibilidad de convertirse en intertexto» [2001: 78].

Dicho esto, ¿qué debe ser considerado exactamente «texto»?, ¿qué clase de objetos semióticos distintos encuentran lugar hacia dentro de una noción amplia de texto? A partir de los estudios de semiótica cultural de Iuri Lotman y Roland Barthes, como es sabido, se han trascendido las estrechas fronteras de una definición meramente lingüística del concepto. Barthes declara en 1968 «la muerte del autor» y descree así de la posibilidad de una autoría por entero original para el texto, su naturaleza vendría a ser entonces esencialmente intertextual, es decir, fundada en el cruce de textualidades diferentes. El texto, señala el semiólogo francés, se aparta así de la obra, por su carácter dinámico, por sustentarse en las asociaciones múltiples que hacen de él un espacio netamente productivo, de juego y de trabajo con el signifi- 
cante, desentendido de cualquier filiación debida al autor [1968]. Lotman coincide con Barthes al aseverar que «todo el conjunto de códigos artísticos, históricamente formados que convierte el texto en portador de significado, corresponde a la esfera de las relaciones extratextuales» [1982: 69]. Pero, además, las indagaciones del lingüista y semiólogo de origen ruso trascienden el interés por lo lingüístico al entender como texto «un complejo heterogéneo y heteroestructural, vale decir, como la manifestación de varios lenguajes a la vez, en que las complejas correlaciones dialógicas y lúdicas entre las variadas subestructuras del texto que constituyen el poliglotismo interno de este son mecanismos de formación de sentido» [1996: 88]. Tal definición engloba el resultado de códigos distintos entre sí y de lo literario, tales como piezas musicales, pictóricas y hasta largometrajes en proyección, como bien señala Ferrari en su libro referido al dialogo entre la letra y la imagen [2007: 12]; con lo cual el dominio de la intertextualidad propiamente dicha extiende significativamente sus alcances. El significado último que subyace tras cada texto, en virtud de las líneas de pensamiento que han desarrollado estos teóricos, solo surge a la luz por intermedio de una colaboración activa del lector, de un consciente cotejo de las relaciones que existen entre aquel y toda una gama de textos, códigos y sistemas de signos peculiares que, desde el fuero externo, lo condicionan internamente. En la presente oportunidad se emprenderá una indagación en este sentido; una búsqueda que tenga su punto de partida en la incorporación y vinculación productiva de discursos diversos, recurso de importancia para la poesía de Wolfe desde sus inicios y durante toda su trayectoria. A estos efectos se ha seleccionado una serie de textos, extraídos de tres poemarios tempranos del autor, Días perdidos en los transportes públicos, Hablando de pintura con un ciego y Arde Babilonia, para registrar en ellos la tendencia antes referida.

Ante tal premisa se hace imperativo, a efectos del análisis, atender a otro concepto crucial como es el de interdiscursividad, que desarrolla 
el filósofo, semiólogo y crítico literario italiano Cesare Segre con el fin de identificar todo nexo semiológico que se suscita entre un texto literario y cualquier objeto producto de esos otros discursos o códigos semióticos diferentes registrados en la cultura y ordenados ideológicamente, como el cine, la música, el teatro, etc. [1985]. Un continuador de las propuestas de Segre, Tomás Albaladejo, reconoce la interdiscursividad como cimiento ineludible para el complejo edificio de la comunicación humana. Según el español, la posibilidad misma del intercambio entre emisor y receptor sería impensable sin el entrecruzamiento de discursividades de índole variada [2005: 28]. En concomitancia con el último concepto mencionado, aparece una noción como la de intermedialidad, que progresivamente ha ganado terreno en la escena teórica al designar la permeabilidad o entrecruzamiento de objetos diferentes, sobre todo en referencia a los mass media. Al estudio de tal categoría se abocó, entre otros, el grupo de estudios sobre literatura y cine (GELYC) de la Universidad de Salamanca encabezado por José Antonio Pérez Bowie. La intermedialidad, noción nueva, resulta fructífera para referir cruces de este estilo. José Seoane Rivera, parte de la formación antes mencionada, asigna en este sentido la etiqueta de intermedial a los «contactos, interferencias o intersecciones entre diferentes medios en una misma obra» [2018: 286]. Antonio Gil González, otro renombrado especialista en estudios intermediales e integrante del GELYC, amplía esta definición primera para señalar explícitamente los alcances de la intermedialidad y distinguir así:

dos formas básicas de manifestación del fenómeno: una intermedialidad intrínseca, consustancial a prácticamente todas las tradiciones y lenguajes artísticos -todos ellos híbridos en mayor o menor medida [...] frente a la intermedialidad propiamente dicha, de carácter extrínseco, que requiere «una transmisión, una combinación, en segundo grado, no solamente entre códigos (la palabra, la imagen, el sonido...), soportes (el libro, la pantalla, el CDrom...), o tecnologías diferentes (las artes gráficas la fotografía o la televisión...), sino entre medios institucionalizados en cuanto tales: entre lite- 
ratura y música o entre las artes plásticas y las escénicas; entre novela y cine, entre cómic y pintura, entre teatro y danza» [2018: 18].

Una escritura tan peculiar como la de Roger Wolfe, hace de la cita, la alusión, la inversión paródica, entre otros procedimientos afines, la base de una praxis poética que salta por encima las vallas de lo meramente literario y a la vez de lo intertextual en su acepción más estrecha. Esto se torna evidente al adentrarse en el análisis de la clase de relaciones complejas que se construyen entre la poesía del autor anglo-español y el plurivalente conjunto de registros y textualidades, diversas entre sí, que son convocadas y puestas a funcionar significativamente a lo largo de su obra. Antes de incurrir en el estudio de la poesía propiamente dicha, vale la pena citar las palabras del mismo autor sobre la importancia del reciclaje de materiales, códigos y discursos variados. En «Ensayoficción», de Todos los monos del mundo, se lee:

Si no sabes hacer poesía, ni prosa narrativa, ni ensayo, ni teoría de la literatura..., ni mucho menos teatro, sino que más bien tan solo eres capaz de representar una especie de comedia permanente, y no te falta la honestidad llamémosle moral para reconocerlo, entonces lo que puedes intentar es revolverlo todo, y a lo mejor tienes algo.

Una tumultuosa y polícroma mescolanza cuya patética diversidad, si al menos tiene un poco de fuerza, o si a fuerza de ser lo suficientemente obsesiva, demoníacamente obsesiva, se reviste de una mínima musculatura, puede alumbrar las tinieblas con algún fogonazo ocasional de luz. Y poco más [Wolfe, 2018: 144].

\section{PINTAR EL POEMA DEL COLOR DEL ROCK}

Roger Wolfe, se ha dicho, suele aludir en su poesía a múltiples discursos diferentes, ajenos, pero a la vez colindantes con lo literario. A lo largo de la tesis que dedica al poeta anglo-español, Juan Miguel López Merino reconoce cómo la expresión wolfiana se dota, progresivamente, de un poemario a otro, de diversas referencias culturales: 
se trata, por supuesto, de un culturalismo vivo y sui generis que no tiene nada que ver con el cultivado por los novísimos o por las promociones de poetas posteriores; es un culturalismo vivido, no impostado, de referentes muy personales, muchas veces irreverente y en el que el mundo del rock tiene tanta importancia como el de cualquier otra manifestación artística. En suma, es un culturalismo que refleja la época en que fueron escritos [2006: 150].

Entre ellos, la música ocupa un espacio de gran relevancia. La ópera, el pop, el country son algunos de los géneros que se hacen lugar en sus versos, pero es el rock, especialmente el rock en inglés, el que se lleva la palma en cuanto a su grado de incidencia en la práctica poética del autor. Es de notar el caso de «Paint it Black», poema del libro Hablando de pintura con un ciego (1992) que coloca al lector en la encrucijada de una primera línea que coincide con el nombre de uno de los mayores hits en la historia de la música contemporánea, mientras el resto del texto rehúsa cualquier mención esclarecedora al respecto. De esta forma, la identificación uno a uno entre poema y single se complejiza, a diferencia de otros ejemplos en los que Wolfe elige explicitar la relación entre determinada pieza musical y su escrito.

«Paint it Black», de la mítica banda británica The Rolling Stones, fue grabada en marzo de 1966 y formó parte de su sexto álbum, $A f-$ termath, de ese mismo año. El sencillo, escrito enteramente entre Jagger y Richards, ocupó durante meses los primeros puestos en las listas de éxitos en Gran Bretaña, en los Estados Unidos y en muchos otros países. Varias curiosidades se dieron cita en su composición, entre ellas, la ocurrencia del instrumentista Brian Jones de emplear para el riff un sitar, instrumento de cuerda proveniente de la India, novedad clave para lograr el tono misterioso y hasta sombrío que acompaña lo ya oscuro de la letra. En relación con esta última, destaca la cuarta línea del estribillo «I have to turn my head until my darkness goes» que, se ha dicho, Jagger habría tomado prestada del Ulises, de James Joyce. 
¿Qué clase de vínculo puede trazarse entonces entre el texto de Wolfe y aquel del sencillo de The Rolling Stones? ¿En qué medida encabezado y cuerpo del poema funcionan entre sí y en esa intersección, o no, con los enunciados particulares de la canción? En primera instancia, desde lo formal, una composición y otra difieren en la persona gramatical elegida. El sencillo escoge la primera para moldear a un sujeto sumido en profunda depresión, quien se lamenta por la pérdida de un ser querido y de ahí que todo lo vea, o deseara ver, en negro. El texto de Wolfe, en cambio, emplea, curiosamente, la segunda persona, como forma de presentar una voz que, desde la experiencia, se refiere a un tercero (bien podría tratarse del propio lector) en igual estado de infelicidad manifiesto.

¿Cómo se construye, en cada composición, el marco en que se refiere ese sufrimiento de un individuo retraído en sí mismo? En este sentido sí se observan similitudes en los procedimientos: el uso del paralelismo sirve al hablante de la canción para insistir en lo desesperanzado de su perspectiva, reforzado por la apelación a lo visual cromático:

I want to see it painted, painted black

black as night, black as coal.

I want to see the sun, blotted out from the sky.

I want to see it painted, painted, painted, painted black.

Despojado de la metáfora cromática, el texto de Wolfe hace uso del paralelismo como medio para caracterizar la penosa existencia con la que vendrían a identificarse el hablante y su interlocutor, voz lírica y potencial lector, incluso poeta y cantante:

Días malos (...)

En los que ves colmillos en las fauces 
de la gente que te dice que te quiere. En los que el sol es un arma arrojadiza o la lluvia una descarga de vinagre. En los que mejor rocías de azufre tu portal. [2008: 97]

Si la solución ante este padecer en el sencillo de The Rolling Stones se reduce a enlazar la negrura del espíritu con la de todo alrededor, el hablante en Wolfe se muestra más expeditivo: ante la hipocresía generalizada y un entorno natural adverso, no queda sino el azufre (de uso extendido como plaguicida y, paradójicamente, como colorante negro en orfebrería), la inacción al abrigo de la cama y el rezo, más como gesto desesperado que verdadero refugio en la religión.

\section{¿QUÉ HACE LA POESÍA EN UN SITIO COMO ÉSTE? ROGER WOLFE Y LA MOVIDA}

En Días perdidos en los transportes públicos, de 1992, Wolfe tematiza la soledad y complejidad de los vínculos entre individuos por medio de la yuxtaposición de poesía, música y cine. El texto «Algo arde, pero no soy yo» se abre con una clara referencia al mundo del rock:

Los Burning cantaban no sé qué historia de no sé qué femme fatale.

Yo contemplaba el rostro de Carmen Maura en el fondo de mi vaso de coñac. [2008: 42]

Burning fue el nombre de una popular banda nacida en Madrid, con influencias de los Rolling Stones, Lou Reed, el blues y el rock de los 50. Creada en 1974 y disuelta en 2019, fue precursora del fenómeno de la "Movida madrileña» durante los 80 y de varios otros grupos en 
las décadas subsiguientes y hasta bien entrado el presente siglo. Sus primeros años, cuando cantaban en idioma inglés, lo mismo que sus raíces, la emparentan, por vías del bilingüismo, con la propia biografía de Roger Wolfe. Con esto se juega en la traducción entre el título y la primera línea («burning» = lo que arde/ardiendo).

Ahora bien, hasta la voz hablante llega confusamente una canción de Burning en particular. Su incapacidad para reconocerla, el repetido «no sé qué», puede explicarse por la hipótesis de que el mencionado no haya sido el primer coñac de la noche. La bebida es un achaque que Wolfe suele atribuir al sujeto que configura en su poesía. Sin embargo, lo particular aquí es que la pista buscada surge ante él en la línea siguiente: Carmen Maura, actriz española consagrada, primera "chica Almodóvar», protagoniza ¿Qué hace una chica como tú en un sitio como éste? de 1978, cinta cuya banda sonora contó con un tema homónimo de Burning que culmina:

Mujer fatal, siempre con problemas...

¿Qué tienes en los ojos, nena, o es que vas a llorar?

Ya sé que alguien pisó tu orgullo en un oscuro portal.

No intentes atraparme, ya he aprendido a volar. [2008: 42]

La escritura de Wolfe anuda en solo una estrofa la tríada poesíamúsica-cine, en afinidad con lo que los estudios intermediales han dado en llamar "intermedialidad extrínseca», es decir, «la presencia efectiva de un medio en otro» [2018: 287]. Sin embargo, la cuestión no se retoma y desaparece ya con la estrofa siguiente. En ella, el sujeto hablante, que parece haber abandonado la soledad acostumbrada, 
cede la palabra a un otro, Ludo. Su voz se registra, primero, en estilo indirecto. Desde la perspectiva propia, una primera persona resume su argumento («Ludo me decía que había tomado / la muy firme decisión de incorporarse / a nuestro club.») [2008: 42]. Luego, a mitad de verso, cita sus expresiones textualmente, su mensaje transita desde una convicción total hasta la más pura resignación: “"Al fin y al cabo -farfullaba- / algún tipo de familia / hay que tener."» [42].

Resulta paradójico notar cómo un sujeto poético que se regocija en la soledad y el silencio, aparece ahora no solo en conversación con un desconocido, sino como parte de cierta sociedad o grupo de dudosa naturaleza. La falta de cualquier explicación deja lugar al interrogante; tal vez la clave para desentrañarlo resida en ese otro elemento ya referido en los primeros versos: el alcohol y, por extensión, la noche. El corte de verso en "había tomado» parece un guiño interesante en esta dirección. Con esto, el intercambio entre la voz y Ludo adquiere un cariz nuevo: la de la discusión entre ebrios, desesperada, pesimista, pero igual de profunda y reveladora. La barra o una mesa cualquiera de un bar innominado suelen ser los atriles predilectos para Wolfe: desde allí lanza sus diatribas filosóficas, existencialistas, punzantes, descorazonadas. Por lo general, la primera persona canalizará su voz, cuando no, momentáneamente tomarán forma figuras como la de Ludo.

Por otra parte, las alusiones a Burning y a Carmen Maura traen consigo la referencia obligada a lo que significó para España la «Movida», que acompañó la Transición luego de la dictadura y muerte de Franco en 1975 y hasta principios de los años ochenta. En conexión directa con un progresivo laicismo de la sociedad española (difusión de métodos anticonceptivos, despenalización de la homosexualidad, auge de los discursos feministas, aumento en el consumo de drogas, etc.), la Movida tuvo un fuerte impacto en la música y el cine. Sin más, Rosa, el personaje interpretado por Maura, recientemente di- 
vorciada, encontrará el amor en medio de este nuevo y alocado ámbito que es la noche de Madrid.

¿De qué manera se coordinan todos estos aspectos en el conjunto del poema? Desde el principio, en la voz incapaz de concentrarse en lo que ve y escucha, en el reflexivo intercambio que mantiene con Ludo y, para cerrar, en la imagen de la calle por la madrugada, se configura todo un cuadro de la bohemia española. El empleo casi exclusivo del pretérito imperfecto a lo largo del texto («cantaban», «contemplaba», «me decía», «farfullaba», «tronaba») genera un efecto de prolongación, de un tiempo que se estira, en correspondencia con jornadas interminables de fiesta que justificaron expresiones de época tales como «Madrid no duerme».

Los versos finales son elocuentes: tras una noche entera en vela, el sujeto vuelve la vista hacia el exterior, hacia una avenida que, con seguridad, lo devolverá al hogar, a la vida rutinaria y exasperante. Sobre el firmamento se imprime, otra vez, lo sonoro. La «gota fría», giro realista de Wolfe sobre el español castellano, remite a un fenómeno meteorológico habitual del otoño peninsular, con tormentas fuertes como la que, se asume, acompañará al hablante de camino a casa.

\section{APOCALIPSIS, ¿NOW? POESÍA Y CINE FRENTE A LA PESADILLA MASSMEDIÁTICA}

La operatoria de Wolfe de servirse de la referencia a un objeto cultural reconocible como primer motor de sentido del poema se repite en «iApocalipsis now!», alusión directa al multipremiado largometraje de 1979 dirigido por Francis Ford Coppola. Apocalipsis now (los signos de exclamación son intervención exclusiva del poeta), inspirada por textos de Joseph Conrad, George Frazer y T. S. Eliot, tiene centro en la locura del coronel Kurtz, interpretado por Marlon Brando, encargado de las 
Fuerzas Especiales estadounidenses en Camboya durante la guerra de Vietnam, y los peligros que significa para la misión que capitanea. Marta Ferrari, en su estudio ya aludido De la letra a la imagen. Narrativas posfranquistas en sus versiones filmicas, reconoce que las relaciones, los intercambios entre el discurso literario y el fílmico han resultado desde siempre enriquecedores y la poética de Wolfe no es la excepción, como se predica de las múltiples instancias y formasen que el poeta procura acercar e intersectar uno y otro código.

De vuelta sobre el poema, los cuestionamientos ante los que se coloca al lector son, en su mayoría, siempre los mismos: ¿cómo se predispone la lectura con semejante encabezado?, ¿qué significados asociados con este se filtran en los versos? Es de interés examinar la naturaleza de ese nexo interdiscursivo entre un objeto y otro que el poeta decide hacer patente desde el título mismo.

El poema se construye a partir de una voz en primera persona que oscila entre la observación de un afuera desolador, meteorológica y humanamente penoso, y un adentro igual de pesimista, dominado por el bombardeo noticioso de la radio. Wolfe reincide en la escena de aquel que, afincado en lo alto de un departamento de ciudad, se detiene a describir lo que sucede en la calle. Pero en esta oportunidad las distancias, los límites entre uno y otro plano se difuminan por intermediación de una conciencia que no solo contempla, sino que relativiza, compara y hasta divaga:

Lo que sobrevive aun de la mañana se desliza lentamente bajo una lluvia inesperada y fina, como en esos sueños en los que no acabas de dormirte. En Canarias, según dicen, es ya la una. Ahí afuera, me parece, las personas son palillos, títeres que maneja una pesadilla colectiva. [2008: 98] 
Predomina entonces la inseguridad, la incertidumbre («según dicen», «me parece»), los objetos se hacen borrosos, sumido todo en una atmósfera onírica, ya entresueño, ya «pesadilla colectiva». En este punto es posible señalar una aproximación entre poema y film: esos estados alterados, entre el sueño, la vigilia, la inconciencia y la alucinación toman plena relevancia en la obra de Coppola, que tuerce progresivamente hacia el delirio, a causa del horror de la guerra, la enfermedad, el uso de drogas y el desquicio por el poder.

El desarrollo, la transición misma de Apocalipsis now encuentra ecos en el poema de Wolfe: del inicio lento, sinuoso, de la lluvia que cae al otro lado de la ventana, el texto se sumerge, líneas después, en un espiral de violencia e irrealidad similar al de la narración del largometraje, conforme avanza la travesía río arriba por la jungla vietnamita:

\footnotetext{
Y en la radio vuelven a la carga una vez más, con la alegría de un niño que se hurga la entrepierna, hablándome y hablándonos de incendios, de desiertos, de ruinas y de muertes y de guerra. [98]
}

A través de la metáfora bélica, de ese «volver a la carga», la radio (preponderante también en el film), como medio masivo, amarillista, introduce, una y otra vez, todo el caos del mundo circundante en el interior que habita el sujeto. En lo grosero de la imagen del niño que se auto complace Wolfe cifra el regodeo de una prensa sensacionalista en que las miserias del hombre ocupan siempre las primeras planas del periódico y los títulos del noticiero. Mediante el recurso de la enumeración, con la repetición de la partícula «de» y la doble conjunción sobre el final «y de muertes / y de guerra» se refuerza el efecto de avasallamiento sobre el receptor en la marea informativa de esta 
época. La disposición que ubica en el último verso, en solitario, a la guerra, eje del filme de Coppola, termina de anudar una obra con la otra en esta peculiar reapropiación que Wolfe hace de una pieza antológica de la historia de la industria cinematográfica estadounidense.

\section{LLAMARSE OTRO, VER AL OTRO. EL ENCUADRE FASSBINDER}

Rainer Werner Fassbinder (1945-1982) fue el nombre de un prolífico director de cine, televisión y teatro alemán, responsable de más de cuarenta películas, dos series y veinticuatro piezas teatrales. También actor, productor y escritor, es considerado uno de los principales representantes del nuevo cine alemán de las décadas del sesenta y setenta, una generación de directores de largometrajes de bajo presupuesto, influenciada por las producciones clásicas de Hollywood y la nueva ola experimental francesa de los años cincuenta. La obra (y vida) de Fassbinder destacó por lo que tuvo de disruptiva, de escandalosa. A sus tramas incorporó, no sin polémica, personajes homosexuales y doppelgängers, además de tratar profundamente cuestiones escabrosas para la época como el fascismo y los prejuicios de género, raza, etc.

¿De qué manera decide Roger Wolfe homenajear al controvertido cineasta en su poema «Los ojos de Fassbinder», parte de Arde Babilonia de 1994? ¿Qué aristas de su figura y su trabajo privilegia en este texto? "Los ojos de Fassbinder», como título, no solo activa en el lector cierta clase de expectativas, un conjunto heterogéneo de saberes vinculados directa o indirectamente al alemán y su cine, sino que redirige primero la atención específicamente hacia su mirada, a «Tus ojos cansados, Rainer, de la vida», verso primero del poema con el que inicia toda una semblanza de Fassbinder: 
-ojos de un color que ignoro o no recuerdo-, ese mostacho, la barba rala, el rostro tierno, tumefacto por el tiempo y sus desmanes [2008: 159]

Sobre las líneas de esa faz se inscribe la cuestión del paso de los años y la memoria, en varios planos de sentido. Por un lado, advierte la voz lírica los efectos nocivos del envejecimiento, de ese «tiempo malo y sus desmanes» que se proyecta en las facciones de Fassbinder, referido en forma coloquial, por su nombre de pila, como si se tratara de un diálogo íntimo o una loa a su persona. Por el otro, el sujeto poético duda respecto al pigmento de los ojos, en parte porque la descripción se deriva de una instantánea en blanco y negro (es decir, de por sí antigua), pero también porque el tiempo opera sobre la propia voz y enturbia su recuerdo, mella su certeza, lo vuelve olvidadizo.

El ejercicio de memoria no se clausura en la contemplación de la imagen, porque el hablante debe indagar en su singular pasado personal, en la genealogía familiar, en el idioma de su bisabuelo, para desentrañar, solo para sí, el mensaje que acompaña la fotografía «Dichter / Schauspieler / Filmenmachen, es decir, poeta, actor, cineasta. Aquí las instancias sujeto de papel y sujeto biográfico «Roger Wolfe» se confunden, se intersectan, así como entran en contacto la figura Fassbinder y esta voz que es cifra del autor anglo-español, acercamiento propiciado por el uso de esa segunda persona de confianza, de familiaridad.

Si la primera parte del poema desarrolla, en tono de atemperada nostalgia, una suerte de conversación entre la voz lírica y ese Fassbinder avejentado de la fotografía, todo cambia con la segunda estrofa. A la ternura con que lo retratara inicialmente le sobrevienen ahora las formas vulgares de la expresión que suele practicar Wolfe, en una 
caracterización segunda, más acorde a la imagen pública asociada al director alemán, un carácter propicio para formar parte del imaginario panteón que esboza en su poesía el autor anglo-español:

Poeta de la polla y de la mierda, monstruo, vándalo, demonio, arcángel, niño de mirada incrédula y pasmada, fantasma encharcado de alcohol y de heroína, amado padre, hermano, ramera, maricona [2008: 159]

La enumeración, violenta, casi desorbitada, funciona a modo descriptivo pero en las antípodas de aquella primera semblanza. En ese encadenamiento se engarzan referentes relacionados a la particular poética y praxis creativa de Fassbinder, lo mismo que cuestiones de índole enteramente personal, en particular su homosexualidad y las adicciones que lo condujeron a una muerte por sobredosis de cocaína y barbitúricos a la temprana edad de treinta y siete años. Se desarrolla aquí una suerte de breve etopeya del director alemán. A la condescendiente prosopografía, como retrato exterior de las cualidades físicas de un sujeto [Miraux, 2005: 49], con la que Wolfe abre el poema, se opone aquí una radiografía, en forma de enumeración, de los claroscuros de una biografía marcada por la experimentación y el exceso.

La palabra vuelve a erigirse en loa, ya no como añoranza de esa mirada enclaustrada en el pasado sino como sentida confraternidad con un mártir, con un precursor en el tratamiento de temáticas harto controversiales, con un verdadero conocedor y vocero de los márgenes sociales, políticos y sexuales. Los últimos tres versos recuperan la cuestión del nombre, refuerzan esa identificación e insisten la trascendencia de ese arte para con la posterioridad: «todos / nos llamamos / como tú». 


\section{FILOSOFÍA Y LITERATURA, ETERNOS STRUGGLE FOR SURVIVAL}

Las indagaciones en las que se embarca la propuesta poética del autor y que traspasan la circunscripción de lo meramente literario no se agotan en cruces con otras esferas de lo artístico (música, cine, pintura, etc.), sino que alcanzan los dominios de otros discursos como lo es, por ejemplo, el de la reflexión filosófica. A lo largo de su obra, no son pocas las instancias en que pensadores y paradigmas ineludibles para la historia de la filosofía son recuperados y reapropiados productivamente, dotándolos siempre de nuevas e inesperadas significaciones.

Como en otros textos analizados previamente, la elección del encabezado del poema en tanto primera operación de sentido resulta fundamental para la escritura de Wolfe, y en el caso de «Eterno retorno», contenido también en Arde Babilonia, se hace evidente por la carga de sentido que conlleva tal noción y en vínculo directo con la clase de escena retratada por el cuerpo del texto. Como concepción filosófica del tiempo, el eterno retorno supone un indetenible repetirse de las cosas en un universo que reiteradamente se extingue para volver a regenerarse. Frente a la cosmovisión occidental, más proclive a una noción lineal de los acontecimientos de la historia, el pensamiento de Oriente se decanta por una explicación cíclica del mundo, por la cual cada recomenzar conduce progresivamente a la perfección final de las cosas. Aun así, el eterno retorno, antes que una sucesión de ciclos idénticos, presupone un reeditarse, sin modificación alguna, del exacto mismo orden de los hechos.

Si bien fueron los estoicos de la antigüedad griega los primeros occidentales en incorporar a su doctrina una concepción como la del eterno retorno, en la contemporaneidad, el filósofo Friedrich Nietzsche la desarrolló en profundidad al volverla base de su pensamiento, desarrollándola en obras fundamentales como La gaya ciencia 
(1882) y Así habló Zaratustra (1885). Según el intelectual alemán, la noción trasciende lo meramente cronológico y se erige en axioma moral para el ser humano, quien solo alcanzará su destino de Übermensch, es decir, de superhombre, si acepta ese devenir repetitivo de la historia y actúa convencido, aun a sabiendas que su hacer, sus pensamientos y hasta sentimientos habrán de reeditarse, idénticos, una y otra vez, en el transcurrir interminable de los siglos.

¿De qué manera recupera el texto de Wolfe todo este complejo entramado filosófico con siglos de reflexión a cuestas? Mediante un pintoresco cuadro del quehacer diario de la voz poética que se repite incesantemente. Ya la línea primera de la estrofa inicial contiene una significativa clave de interpretación: «Desayunar con Nietzsche». El sujeto, en acostumbrada situación de lectura, da principio al periplo del día con la referencia al ya mentado pensador del eterno retorno y, junto a ella, la relación de lo rutinario de su existir: ciertas adicciones (el tabaco, el café), la soledad (mitigada solo por la presencia omnímoda del perro) y las obligaciones financieras actuales que amenazan interferir con funciones fisiológicas primordiales como la deglución.

A la reseña del desayuno le sigue otra imagen, la de «El almuerzo, cénit / de los días», en esa concatenación de comidas a la que pareciera reducirse el transcurrir de jornadas indistinguibles entre sí. Efímero se demuestra el entusiasmo que antes animara al sujeto:

\author{
-abatido el asomo \\ de sano optimismo mañanero \\ por dispositivos infernales \\ que adoptan formas sucesivas \\ de teléfono, timbrazo, \\ zancadilla callejera, \\ gente puesta en fila, \\ el sordo ronroneo \\ de un PC- [2008: 161]
}


Agobiado por este tortuoso conjunto de martirios cuya repetición impone la cotidianeidad contemporánea no queda a la primera persona más que reconocer «que la vida / es struggle for survival» citando, en estilo indirecto, al segundo de los formadores de pensamiento que convoca Wolfe en «Eterno retorno»: Charles Darwin. La voz elige introducir, fuera de su contexto de origen, estrictamente erudito, la noción de lucha por la supervivencia, fundamental en la teoría darwinista de las especies, según la cual, para toda planta y animal, hay un número excedente de individuos, por lo cual se encuentra siempre en riesgo la subsistencia de cada uno. La selección natural opera entonces preservando a aquellos ejemplares que sufren modificaciones que los favorecen en esa competencia, modificaciones que se mantienen y se transmiten por vía hereditaria. Pero para el hombre que delinea el poeta anglo-español, la misma existencia diaria, por lo repetitiva, termina por volvérsele insostenible al sujeto.

Así es como, conforme la progresión del día (uno cualquiera, que no es sino eterno retorno de iguales jornadas anteriores), lo que fuera un amanecer placentero junto a Nietzsche deviene por la noche una simulación triste y sinsentido:

\author{
Y finalmente, horas más tarde, \\ tras el dudoso ensayo \\ de ascesis imposible \\ que a veces llamo cena \\ Schopenhauer me conduce \\ renqueante y roto \\ hacia la cama [2008: 161-162]
}

Con el ocaso todo parece perder materialidad; el alimento, como el cuerpo, carecen de sustento; la austeridad de asceta, el hambre y el dolor desvían la expresión hacia un fuerte desánimo, coherente con la tercera figura involucrada en el poema, Arthur Schopenhauer, prominente 
pensador alemán del siglo XIX, principal representante del pesimismo filosófico. El mismo Schopenhauer quien, en El mundo como voluntad $y$ representación, reflexionó en relación con la cuestión del eterno retorno y ejerció fuerte influencia sobre las teorizaciones posteriores de muchos otros intelectuales, entre ellos, el propio Nietzsche. Curiosamente, el escrito de Wolfe, inaugurado con una mención de Nietzsche, empieza a cerrarse, como si se tratara de un ciclo inacabable, con la referencia a Schopenhauer, precursor de aquel primero.

Pero los avatares de este vivir rutinario que es materialización del eterno retorno contemporáneo solo culminan al intercalarse, murmurante, el discurso de un sabio último, mas ahora uno de índole ficcional. Es Hamlet, creación del "gran Will Shakespeare», quien, abrumado por la posibilidad de que, aun muerto, las cosas vuelvan a repetirse eternamente para él en el sueño, se cuestiona: «To die, to sleep - / to sleep, perchance to dream - (ay, there's the rub, for in this sleep of death what dreams may come...». La inserción de un nuevo discurso ficcional, de esa nota literaria última, ha de vincularse directamente con la incorporación anterior de otras voces. Porque el mismo protagonista de la tragedia shakespeariana reconoce y teme la reiteración interminable de cosas que regresan, se repiten, se reutilizan. Pero, además, tal recuperación puede funcionar significativamente y repensarse en cruce con el resto de las reapropiaciones revisadas hasta este punto en poemas anteriores. Los heterogéneos materiales de los que se sirve Wolfe vuelven, reinterpretados, a su praxis en un movimiento circular que es equiparable al de aquello que insiste en retornar, constante e indefectiblemente.

\section{CONCLUSIONES}

Al finalizar este recorrido por algunos de los vínculos interdiscursivos, diseminados a lo largo de toda la obra de Wolfe, se ha pretendi- 
do dar cuenta de lo crucial que se muestra, para el quehacer poético del autor, la manipulación de discursos y/o registros externos al ámbito de lo estrictamente literario. Como ya señalara López Merino, esta particular operatoria, lejos de mermar con el paso del tiempo, se acentúa conforme ven la luz nuevos volúmenes de su poesía. En este sentido, títulos últimos -que exceden los propósitos del actual trabajo, pero que al menos deben ser mencionados- tales como Gran esperanza un tiempo (2013), El amor y media vuelta (2014), Pasos en el corredor (2016) y El árbol del inglés (2021), entre otros, abundan en ejemplos que son evidencia de la relevancia que aún guarda para a escritura wolfiana esa recuperación de códigos otros.

Hits del rock local e internacional, lo mismo que piezas antológicas del séptimo arte, de Coppola a Fassbinder y el español Fernando Colomo, en los textos seleccionados, pero también en muchos otros, se convierten en blanco predilecto, en material maleable para una maquinaria wolfiana de reapropiaciones que encuentra y extrae de ellos sentidos novedosos, insospechados. Y es que no existen límites para esa operatoria de recuperación, de deglución universal de discursos que alcanza incluso a la filosofía de Nietzsche, a Schopenhauer y al evolucionismo de raíz darwiniana.

En un trabajo ya ineludible en relación con la literatura española de las últimas décadas, el fundamental texto «Un realismo posmoderno», de Joan Oleza, se señala con lucidez que un sector del pensamiento posmoderno ha identificado como consustancial a él «la reapropiación de la tradición, la disolución de la incompatibilidad modernista entre cultura de elite y cultura de masas y la exploración y recuperación de formas, temas y procedimientos de la cultura popular de masas» [1996: 40]. Por su parte, Laura Scarano continúa las reflexiones de Oleza y se pregunta: «¿Cuál es en definitiva la concepción del arte y del lenguaje sobre la cual se eleva el edificio estético de la posmodernidad?» [2000: 267] y, a modo de síntesis, recupera una serie de dogmas reconsiderados: 
«Pensamiento débil» (Vattimo) en tanto huye de fundamentalismos y dogmas, «nueva historicidad» (sin la teleología del progreso indefinido), pastiche y collage al servicio de un afán lúdico que magistralmente retrata Eco: «La respuesta posmoderna a lo moderno consiste en reconocer que, puesto que el pasado no puede destruirse -su destrucción conduce al silencio-, lo que hay que hacer es volver a visitarlo; con ironía, sin ingenuidad» [2000: 272].

La praxis de Wolfe, en correspondencia con esta lógica, desconoce las barreras entre medios y géneros para hacer lugar, junto a la reinterpretación de tópicos clásicos de la literatura universal, entre otras cosas, a la filosofía y la ciencia, pero, y sobre todo, a otras textualidades; estas habían sido largamente desatendidas o dejadas de lado como subproductos vulgares de la masificación cultural, como es el caso del cine, ya de índole experimental o de taquilla, el rock anglosajón y la música "comercial» española de los 70 . El propio poeta señala al respecto en Tiempos muertos, uno de sus volúmenes de «ensayo-ficción», que «el escritor desconoce el desperdicio, que su existencia es un ejercicio permanente de acaparamiento y reciclaje, todo es bueno para él, todo es útil para su obra» [2009]. La escritura misma tiende así a pluralizarse y todo aquello que se asocia con «lo poético» se complejiza por la convocatoria productiva de códigos diversos, en una exploración verdaderamente integral, interdiscursiva e intermedial, productiva y fecunda para proponer una nueva mirada sobre la polémica escritura que se abre camino en la poesía española de las últimas décadas.

\section{BIBLIOGRAFÍA}

Albaladejo, Tomás (2005): «Retórica, comunicación, interdiscursividad», Revista de investigación lingüística, 3: 7-33.

BARTHES, Roland (1984): «De la obra al texto», en El susurro del lenguaje. Más allá de la palabra y la escritura, Barcelona, Paidós. 


\section{LA POESÍA TEMPRANA DE ROGER WOLFE}

(1984): «La muerte del autor», El susurro del lenguaje. Más allá de la palabra y la escritura, Barcelona, Paidós.

FERRARI, Marta (ed.) (2007): De la letra a la imagen. Narrativas posfranquistas en sus versiones fílmicas, Mar del Plata, Editorial de la Universidad Nacional de Mar del Plata (EUDEM).

Genette, Gerard (1989): Palimpsestos. La literatura en segundo grado, Madrid, Taurus.

Gil GonZÁlez, Antonio y PARDO, Pedro (2018): «Intermedialidad. Modelo para armar», en Adaptación 2.0. Estudios comparados sobre intermedialidad, ed. A. Gil González y P. Pardo P., (Binges, Orbis Tertius), 1138

LóPeZ MERINO, Juan Miguel (2006): Roger Wolfe y el neorrealismo español del siglo XX, Zaragoza, Pórtico.

(2005): «Sobre la presencia de Roger Wolfe en la poesía española (19902000) y revisión del marbete "realismo sucio"», Espéculo. Revista de estudios literarios, Madrid, Universidad Complutense de Madrid, http://www.ucm.es/info/especulo/numero31/rogwolfe.html [08/09/2021].

Lotman, Iuri (1996): La semiosfera. Semiótica de la cultura y el texto, Madrid, Cátedra.

(1982): La estructura del texto artístico, Madrid, Ediciones Istmo.

MARTÍNEZ FERNÁNDEZ, José Enrique (2001): La intertextualidad literaria, Madrid, Cátedra.

MirauX, Jean-Philippe. (2005): La autobiografía: Las escrituras del yo, Buenos Aires, Nueva Visión.

OlEZA, Joan (1996): «Un realismo posmoderno», Ínsula, 589-590: 39-42

SCARANO, Laura (2000): «La otra posmodernidad (Reflexiones sobre España desde Argentina)», CELEHIS-Revista del Centro de Letras Hispanoamericanas, 12: 257-281.

SEGRE, Cesare (1985): Principios de análisis del texto literario, Barcelona, Editorial Crítica.

SEOANE Rivera, José (2018): «Breve diccionario intermedial.», en Adaptación 2.0. Estudios comparados sobre intermedialidad, ed. A. Gil González y P. Pardo P. (Binges, Orbis Tertius), 279-299

Wolfe, Roger (2018): Todos los monos del mundo, Sevilla, Editorial Renacimiento.

(2015): «Roger Wolfe: Cuando el alma grita», Entrevistado por Juanjo Ordás, Efe Eme. Diario de actualidad de música, https://www.efeeme.com/roger-wolfe-cuando-el-alma-grita/ [08-09-2021]. 


\section{MARIANO DOMINGO}

(2009): Tiempos muertos, Barcelona, HUACANAMO

(2008): Noches de blanco papel (Poesía 1986-2001), Barcelona, HUACANAMO. 